\title{
AVALIAÇÃO DE WEBSITES POR PESSOAS COM DEFICIÊNCIA DE APRENDIZAGEM ${ }^{1}$
}

\section{EVALUACIÓN DE SITIOS WEB PARA PERSONAS CON DIFICULTAD DE APRENDIZAJE}

\author{
Peter Edward Williams - peter.williams@ucl.ac.uk \\ PHD em Information Science. Professor do Department of Information \\ Studies da University College London, Inglaterra.
}

\section{RESUMO}

Introdução: O crescente corpo de literatura reconhece o valor da World Wide Web como uma ferramenta que pode ser utilizada para o auxílio de pessoas com deficiência o acesso a aprendizagem relevante e adequadamente escrita e apresentada informações.

Objetivo: Analisar as preferências do site de pessoas com dificuldades de aprendizagem, os métodos utilizados e as dificuldades metodológicas para induzir as preferências desse público.

Metodologia: As questões metodológicas inerentes foram o uso do sistema de classificação e a técnica de entrevista.

Resultados: Os participantes reconheceram que dois dos três locais são como um círculo de destaque, e eles enfatizaram a sua preferência para o uso de imagens, especialmente à medida que foram tomadas por eles. O grupo também contou com jovens com dificuldades de aprendizagem em si. Quanto posicionamento do menu, o arranjo horizontal foi em sua maioria preferido para a vertical, e a estrutura de menu circular invulgar de um dos locais foi muito apreciado.

Conclusões: Foram verificadas as preferências dos usuários com dificuldade de aprendizagem nos websites por meio do sistema de classificação. Houve dúvidas sobre a eficácia do sistema de classificação original empregado. Contudo, apenas uma quantidade mínima de informações pode ser provocada pela entrevista. E combinado com questionando foi possível extrair informações consideráveis de pessoas que possuem dificuldades para articular suas opiniões.

1 Traduzido por: Dra. Ana Carolina Simionato - Doutora em Ciência da Informação pela Unesp/Marília. Docente da Universidade Federal de São Carlos - UFSCar. 
Palavras-chave: Usabilidade. Dificuldades de aprendizagem. Avaliação de websites. Deficientes de aprendizagem.

\section{INTRODUÇÃO}

O crescente fluxo de literatura reconhece o valor da World Wide Web como uma ferramenta que pode ser utilizada para auxiliar as pessoas com deficiência, além de acessar informações relevantes e apropriadamente escritas e apresentadas, segundo os autores Fanou (2008); Matausch; Peboeck (2010), Minnion et al (2006).

Entre a literatura encontrada, pouco tem sido relatado sobre a praticidade que as páginas Web devem ter - são exemplos raros os de autores como Sevilla et al, (2007); Rotondi et al (2007) - e nesse parâmetro há menos ainda literatura sobre o que tem sido analisado sobre as preferências dos usuários com deficiências intelectuais.

Uma página Web com as informações mais relevantes e acessíveis será menos utilizada se ela não é atraente em termos de sua aparência ou estrutura. Isso é lamentável, pois a ideia de escolha e preferência pessoal tem estado na vanguarda do debate a respeito, em particular, a prestação de serviços, pelo menos desde uma publicação do governo do Reino Unido sobre "valorização das pessoas" (Valuing People) em 2001, em que 'escolha' é um dos quatro princípios orientadores para a política central do governo do Reino Unido.

Este artigo procura analisar as dificuldades metodológicas e as preferências de pessoas com dificuldades de aprendizagem no contexto de websites e descreve um projeto de pesquisa que testou a eficácia de dois métodos projetados para esta finalidade. $\mathrm{O}$ estudo faz parte de um programa de pesquisa de grande escala, que se preocupa com o desenvolvimento de um website que possa fornecer informações acessíveis e relevantes sobre temas relacionados com a vida independente para as pessoas com dificuldades de aprendizagem e seus pais e cuidadores.

O condutor inicial foi o The road ahead, que consiste em dois relatórios (TARLETON, 2004, TOWNLEY, 2004) baseados na literatura disponível e em 'transição' (ou seja, a partir do ambiente suportado de escola ou faculdade para o mais independente mundo da vida adulta). "[...] há poucas informações que apoiam 
os jovens a estar no comando de suas vidas" (TARLETON, 2004, p. 60). "Muitas destas informações encontradas (relatórios, livros e sites) não são [...] facilmente acessíveis e disponíveis aos jovens e às famílias [...]" (TOWNSLEY, 2004, p. 50).

No mesmo sentido, o website Newham Easy Read ('Newham Leitura Fácil' a www.newhameasyread.org) foi criado pelo Centro Rix da Universidade de East London. O autor deste artigo esteve envolvido em seu desenvolvimento, delineado em Minnion et al (2008), com o trabalho especificamente da praticidade em examinar os aspectos encontrados de usabilidade em Williams e Hanson-Baldauf (2010) e Williams (2010 e 2013). Newham Easy Read, apesar de atender a uma necessidade identificada em The Road Ahead, não é uma forma exclusiva no fornecimento de dados baseado na Web para pessoas com dificuldades de aprendizagem.

Outros locais incluem 'movingonup' e 'Dobsons Choice' e Wales Easyread, disponível pelo endereço https://www.easyreadhealthwales.org.uk/ e Mencap www.mencap.org.uk/. Este estudo inclui a consideração dos dois primeiros desses sites, juntamente com Newham Easy Read e uma adaptação do mesmo, além do site de Newham Borough Council pelo público em geral. Um site 'geral' é adaptado para evitar que a suposição de sites 'acessíveis' fosse mais interessante e também porque a grande maioria dos sites que os participantes (e, de fato, qualquer um) vão descobrir na Web não irá ser escrita com eles em mente como audiência.

O objetivo do projeto é explorar as formas de extrair informações na utilização do Newham Easy Read por pessoas com dificuldade de aprendizado leve e suas preferências de websites. O estudo foi realizado em duas partes, com os resultados da primeira parte informando o segundo turno.

Pesquisas sobre as preferências das pessoas com deficiência de aprendizagem, em termos de design do site ou conteúdo, têm sido mínimas. Um dos únicos estudos que buscou preferências do usuário sobre o design do site e vocabulário usado foi o de Rotondi et al (2007) e aparentemente não foram tomadas medidas para facilitar as preferências. Entre essas medidas estão a escala de classificação e um questionário cuidadosamente redigido. Mas Rotondi et al (2007) aperfeiçoaram o site, oferecendo uma maior praticidade ao invés de considerações preferenciais. Além desta abordagem 'global' de Rotondi et al (2007), há Choi e Bakken (2010) que pediram aos participantes para escolher entre fotos e clip-art em páginas de informações na Web. 
Alguns pesquisadores também tentaram medir a 'satisfação' - por exemplo, Sevilla et al (2007); Karreman et al (2007). Embora tal atividade seja louvável em si, ambos os estudos citados compararam 'acessível' ou 'adaptado' com o mainstream, ou 'não-adaptados' locais. Karreman et al (2007) assumiram preferências através das diferenças de classificação atribuída a vários aspectos de cada local, verificaram como os participantes empreenderam uma série de tarefas postas. Sevilla et al (2007) mediram a satisfação de vinte participantes com deficiências cognitivas, analisou como eles realizaram várias atividades baseadas na Web, observando sinais como o número de gestos de reclamações ou de falta de interesse, o número de comentários positivos ou negativos, etc. Os resultados de uma versão convencional e adaptada do site foram comparados estatisticamente para apurar preferências.

Assim, mais uma vez, os participantes não foram convidados diretamente para dar suas preferências. Outra literatura tem se preocupado com profundidade em temas que vão além do design do site ou conteúdo, com temas geralmente relacionados a questões importantes de necessidades e opiniões diárias, ao invés de escolhas de Tl. Essas têm sido, principalmente, em termos de comunicação e outras dificuldades que se apresentam na comunicação com as pessoas que têm meios limitados de se expressar e garantir a prestação de serviços que atenda às suas necessidades expressas. (BARKBY et al, 2009, BOYDEN et al, 2013).

Em sua maioria, as pesquisas (BREWSTER, 2004, BOOTH; BOOTH, 1996) entrevistam pessoas com pouco ou nenhum discurso - uma proeza que não foi tentada para a pesquisa atual. Mesmo as pessoas capazes de se comunicar razoavelmente bem podem ter problemas na articulação e não responder quando confrontado com perguntas abertas (BOOTH; BOOTH, 1996). Uma solução para aqueles que acham particularmente difícil se comunicar é o auxílio visual de placas de sinalização (LEWIS et al,2008) ou cartas colocadas numa tábua ou mesa (MURPHY, 1997; MURPHY; CAMERON, 2002).

Para aqueles que poderiam participar de uma entrevista informal ainda existem dois problemas destacados na literatura. O primeiro é o de ser mal representado por entrevistadores (intencionalmente ou não) e por ser 'possível' um viés de aquiescência dos entrevistados, segundo Antaki et al (2002), que mostraram isso em sua análise de entrevistas realizadas pelos participantes deficientes e 
reformularam as respostas com o propósito de mostrá-las de uma forma mais positiva.

O segundo problema na entrevista é o 'viés aquiescência'. Este é o fenômeno de concordar com um pesquisador (ou, na verdade, alguém com autoridade real ou percebida) com pouca atenção às questões dadas. Meisenberg e Williams (2008) descobriram que os indivíduos que demonstram um viés aquiescência tendem a ter nível inferior de educação e inteligência. Heal e Sigelman (1995) notam uma tendência deste grupo em concorrer com perguntas fechadas - um fenômeno resumido por Sigelman e colegas (SIGELMAN et al, 1981) como 'em caso de dúvida, diga sim'.

Como Finlay et al (2008, p. 354) notam, baseados em um estudo etnográfico de nove meses de escolha e controle em serviços residenciais, quando as compreensões verbais são limitadas e funcionais, os pesquisadores devem decidir se a pessoa está realmente escolhendo ou se está simplesmente dizendo algo que ela tenha conhecimento, mesmo quando o é irrelevante. Heal e Sigelman (1995, p. 339) sugerem que "[...] tolerância pelos entrevistados com participantes com retardamento mental [pode ser] contornada pela reformulação de perguntas 'sim/não' para um formato de múltipla-escolha 'isto/ou aquilo'." Os autores também dizem que, "embora, perguntas induzam seu próprio viés - uma disposição para os participantes selecionarem a última das duas opções, independentemente do conteúdo deste viés, não era tão grande quanto o viés aquiescência." (HEAL; SIGELMAN, 1995, p. 339).

\section{METODOLOGIA}

\subsection{Amostra}

Doze jovens (18 - 22 anos; 8 homens) de diversos cursos relacionados a 'transição' fizeram parte desse teste. A primeira sessão de trabalho de campo se realizou em uma Escola Especial de Nível Superior na Inglaterra. Os participantes estavam trabalhando ou em breve estariam à procura de emprego apoiado. A segunda rodada foi dividida entre dois locais: a mesma Escola - embora com alunos diferentes - e um Centro de Dia, no bairro da cidade de Londres, o Enfield, onde os participantes estavam à procura de trabalho ou já estavam em tempo parcial trabalhando. 
Sete estudantes da universidade (entre as idades de 18 e 21) e seis do Centro de Dia (20 e 28) participaram do evento. Os participantes de ambas as sessões foram todos classificados pelo colégio como tendo "dificuldade de aprendizado leve". A principal característica deste grupo é um ritmo mais lento da linguagem e de desenvolvimento social em relação àqueles sem nenhuma deficiência. Eles possuem um nível de alfabetização básica e habilidades numéricas e, com o apoio adicional, vivem de forma independente e levam uma vida razoavelmente normal (BEIRNE-SMITH et al, 2005). Os participantes para este estudo não tinham deficiência física e não necessitam de acessibilidade inventada.

\section{Equipamento:}

Para ambas as sessões foram utilizados computadores em rede padrão, repartidas de um-para-um.

\section{Sites analisados:}

- Para a primeira sessão, dois sites foram escolhidos para comparar com o original Newham Easy Read. Estes foram:

- Movingonup: www.movingonup.info;

- Newham Borough Council: www.newham.gov.uk.

Para o segundo turno, Movingonup foi mantido e ainda:

- Uma versão adaptada do Newham Easy Read (denominado como Pete Easy Read);

- Escolha de Dobson: www.dobsonschoice.co.uk/

Estas escolhas foram feitas por várias razões, como descrito abaixo, juntamente com a descrição geral de cada local.

Todos esses sites, exceto (surpreendentemente) a Escolha de Dobson, continham informações relacionadas com 'vagas de empregos', que vão desde os passos necessários para encontrar um emprego, vagas específicas, e aconselhamento de carreira. Uma descrição de cada um cabe a seguir:

Newham Easy Read: Este site não foi criado apenas para atender às necessidades de pessoas com deficiências de aprendizagem, mas foi escrito com 
elas e, quando possível, por elas. O conteúdo do texto foi mantido a um mínimo e é acompanhado por uma versão de áudio equivalente. As imagens foram também usadas livremente, conforme recomendado na acessibilidade literária (por exemplo: W3C, 2008). Cada entrada de conteúdo (ou 'menu') listada vincula a submenu de páginas feitas por um de uma série de grupos com os quais o recurso foi criado. Estes incluem pessoas em centros dirigidos por voluntários; escolas para adultos com deficiências; e um centro de emprego especialista. Acessando um dos links da página do submenu leva a uma outra página de informações de três ou quatro frases curtas acompanhadas de fotografias. Por exemplo, uma das seções principais é do dinheiro, no submenu está incluso 'uso duma máquina de dinheiro'.

A página de informações acessada por este menu oferece instruções simples e conselhos, como exemplo: 'sempre tente usar máquina de dinheiro à luz do dia'. $\mathrm{E}$ inclui fotos dos criadores da página, demonstrando o uso de uma máquina desse tipo. A página original pode ser vista na figura 1.

\section{Figura 1 - Página inicial do Newham Easy Read}

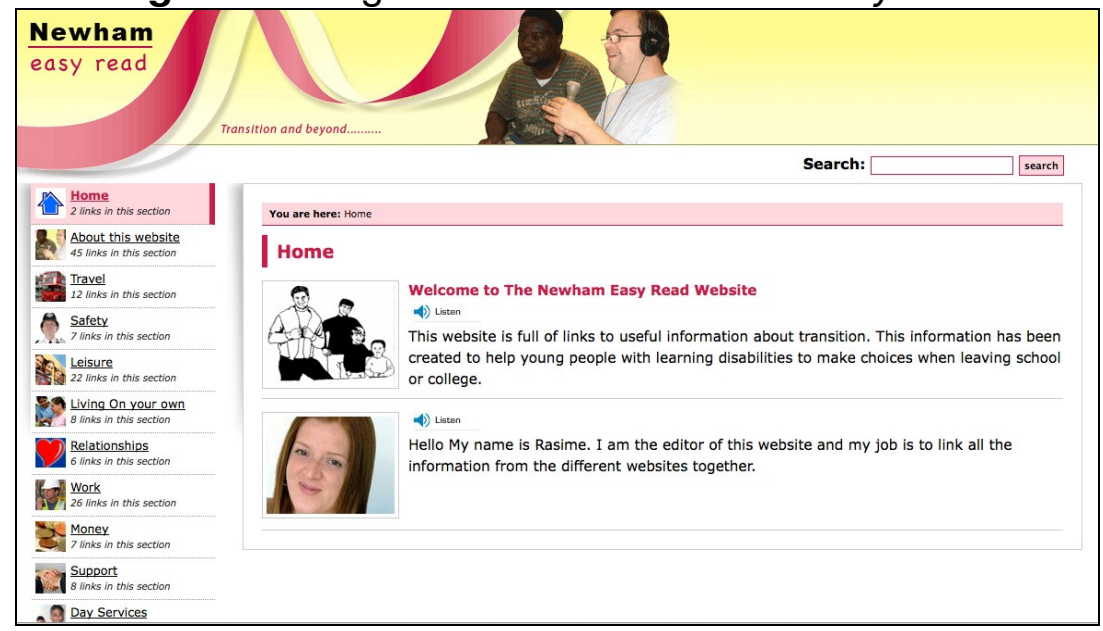

Fonte: www.newhameasyread.org (2012).

Pete Easy Read: após vários ensaios de Newham Easy Read, incluindo testes de praticidade (WILLIAMS; HANSON-BALDAUF, 2010; WILLIAMS, 2013a, 2013b) de Pete Easy Read, foi desenvolvido um site experimental, que não está em acesso aberto. $\mathrm{O}$ site foi criado abordando questões sobre a primeira rodada e em estudos de usabilidade anteriores. Havia menos itens no menu; colocação menu foi horizontal (exceto para a página inicial, onde foi utilizada uma grade de arranjos); havia texto maior e as fotos (ao invés de ícones) foram utilizadas por toda parte. $\mathrm{O}$ 
conteúdo é semelhante ao do site original de Newham Easy Read e também foi escrito com as pessoas com dificuldades de aprendizagem.

É possível visualizar a grade de menus (a página inicial) e uma das páginas de informações na figura 2.

Figura 2 - Página inicial do Pete Easy Read

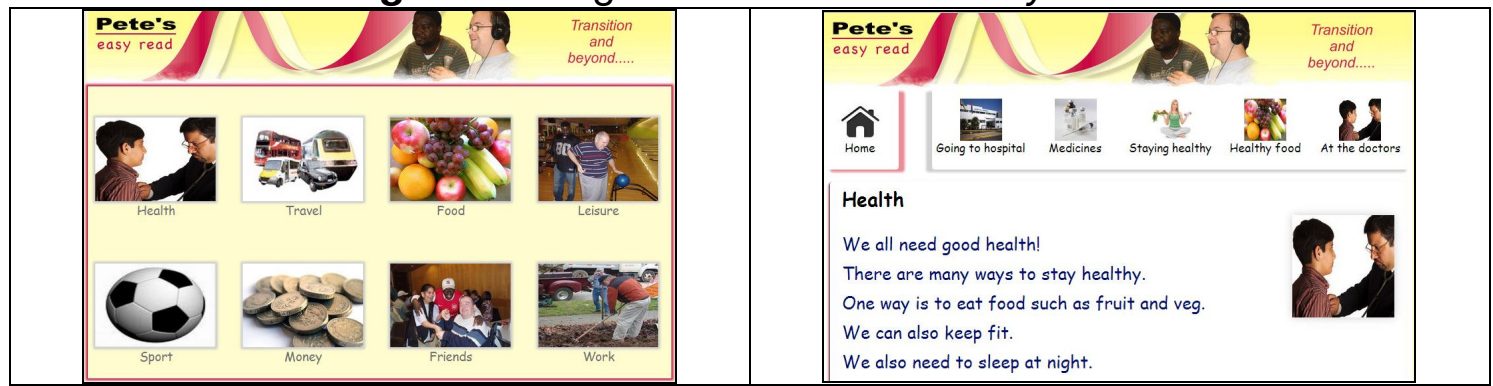

Fonte: Elaborado pelo Autor.

Movingonup: este site foi desenvolvido para o mesmo grupo de Newham Easy Read (pessoas com deficiência mental). Em segundo lugar, são também tratados os mesmos problemas, ou seja, aqueles em torno de transição. Em terceiro lugar, é usado um esquema muito diferente e há um sistema de navegação para Newham Leitura Fácil, por esse motivo, um site ideal para a comparação que foi feita. A característica distintiva deste site era o estilo de menu circular adotado para a página de sua 'casa' e as principais páginas de cada uma de suas seções. Tal arranjo elimina a necessidade de rolar a página (pelo menos das telas que foram vistas pelos participantes do estudo).

De certa maneira, isto também pode ser visto como a remoção de qualquer tipo de hierarquia tópico, presente em uma lista vertical dentro da qual a entrada, na parte superior, pode ser indevidamente considerada para ter maior importância do que a proporção abaixo. $\mathrm{O}$ menu pode ser visto na Figura 3. A página de informações não exige rolagem de página também. O conteúdo de cada página só ocupava a parte visível. Setas foram usadas para acessar o resto do conteúdo que seguiria na próxima página. 
Figura 3 - Página Movingonup mostrando o menu circular

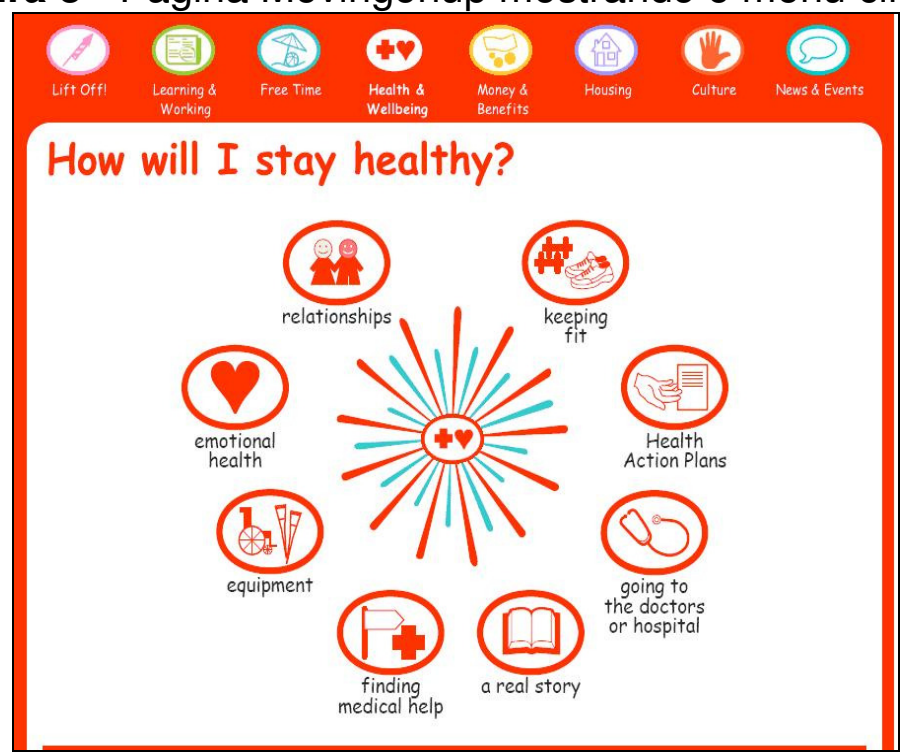

Fonte: www.movingonup.info (2012).

É digno de mencionar, como participantes mencionaram isso, que as páginas internas adotaram uma estrutura de menu horizontal mais comum (ver Figura 4).

Figura 4 - Página Movingonup (detalhe), mostrando o menu horizontal

Culture Learning \& Working Free Time

Fonte: www.movingonup.info (2012).

A segunda característica distintiva da Movingonup é a presença de ícones simples de desenho de linha utilizados como marcadores de conteúdo, ao invés de fotos, como o usado no Newham Leitura Fácil. Cada página é luz sobre texto. Para facilitar isso, cada tópico é dividido em várias páginas, com setas para trás e para frente no pé de cada página. As informações sobre a maioria das páginas estão organizadas em pontos de bala.

Newham Borough Council: Site mainstream Newham Borough Council também foi escolhido principalmente porque contrastou com os outros dois locais na medida em que forneceu informações mais em um nível mainstream. Isso foi considerado um recurso apropriado, apesar deste fato, como muitos sites para pessoas com Dificuldades de Aprendizagem - como Movingonup e Escolha de Dobson (um site utilizado na segunda rodada do estudo) - atuam como locais Portal que levam a fontes tradicionais. Na verdade, este último não inclui uma página de 
informações em si, apenas fornece uma porta de entrada para os outros. Assim, muitas pessoas que usam sites ainda especificamente orientados para as pessoas com baixos níveis de alfabetização iriam, de qualquer maneira, ter que negociar sites mainstream, simplesmente por serem conduzidas para lá através de hiperlinks.

O site oferece uma riqueza de informações sobre emprego, incluindo vagas, como preencher um formulário e escrever um CV e informações sobre entrevistas de emprego. Há listas de menu em ambos os lados da página. No lado esquerdo o usuário é convidado a 'Navegar pelos serviços (Benefícios e Pagamentos; Cidadania e Nacionalidade etc.) No outro lado, estão mais entradas "interativos" sobre, por exemplo, Conselho fiscal, no momento do teste (abril de 2011), embora não mais, a estrutura também foi muito hierárquica. Uma vez que um item de conteúdo principal foi escolhido, como "Empregos e Benefícios", um submenu abre a sua direita, neste caso, com cinco opções: Benefícios, Orientação Profissional, Igualdade e Diversidade, Centros de Emprego, emprego no Conselho e Treinamento \& desenvolvimento. Há um submenu a partir daqui também.

O site foi criado com acessibilidade em mente. Cada página, por exemplo, tem um Sorrisômetro - facilidade de classificação, e um menu interativo e acessível sobre o direito de cada página. Isso realmente melhorou desde o momento do teste, no entanto, anteriormente era preciso ativar o link 'fazê-lo online' antes de chegar a um menu similar, e, portanto, tinha um passo extra para negociar. A página inicial é mostrada na figura 5 .

\section{Figura 5 - Página inicial do Newham Borough Council}

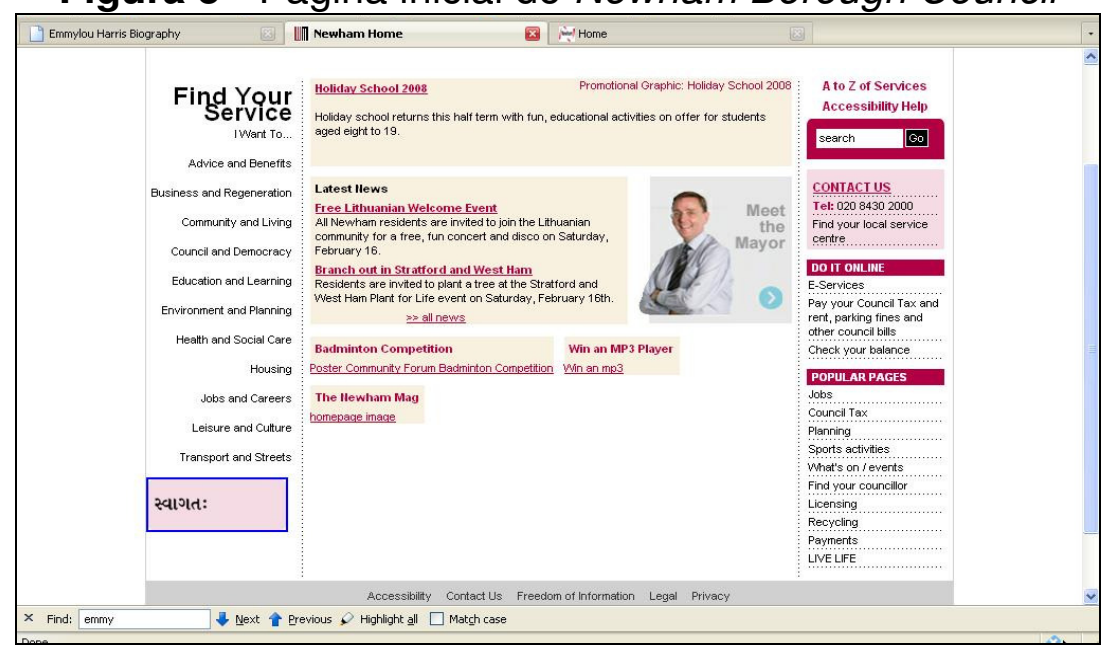

Fonte: www.newham.gov.uk (2012). 
Escolha de Dobson: Escolha de Dobson inclui links para sites sobre muitos temas gerais relativos à transição. Este site é puramente um portal para outros sites, a maioria dos quais (por exemplo, a Transport for London, Amy Winehouse etc.) não são projetados para pessoas com dificuldades de aprendizagem. Apesar disso, foi considerado útil para o estudo em razão de ser desenvolvido para a comunidade alvo de usuários, que utilizou um menu grade em formato de áudio e empregado para aumentar, ao invés de simplesmente ler o texto nas suas páginas próprias. Ambas as características são mantidas nas páginas do submenu. A Figura 6 mostra tanto a casa quanto uma página de submenu para este site. Como pode ser visto, na home page (à esquerda), existem duas áreas em branco para o lado do menu principal. Estas são preenchidas nas páginas submenu (à direita) por um título submenu - Entretenimento neste caso - e links para sites externos.

Figura 6 - Página inicial do site Escolha do Dobson e página submenu para 0 entretenimento.

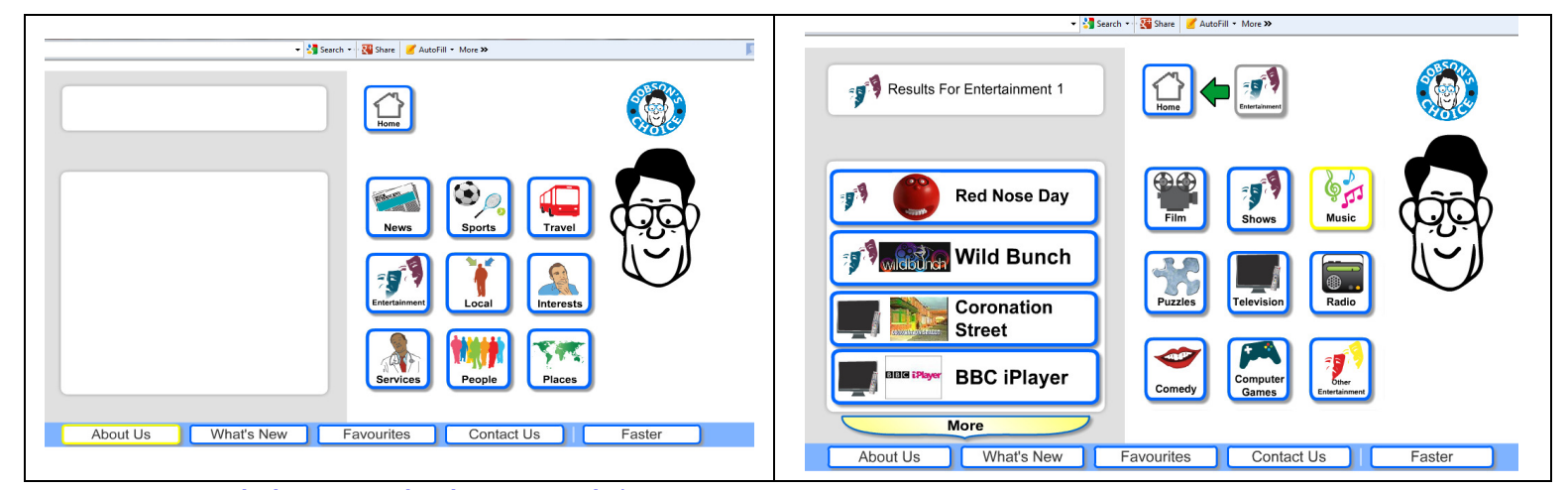

Fonte: www.dobsonschoice.co.uk/ (2012).

Um clique em um item do menu (as pequenas caixas mostradas na Figura 6) faz com que o rosto do lado direito explique que o link é acompanhado pelo aparecimento de um balão de fala com as palavras, por escrito. Para realmente ativar o link, a área precisa ser clicada novamente.

\section{Método}

Os participantes receberam um briefing sobre o projeto de um grupo que discutiu os diferentes sites investigados e a finalidade do estudo. Eles, então, receberam uma demonstração de como fazer a avaliação. Isto incluiu usando um 'sorrisômetro'; sistema de classificação (descrito abaixo) e formulário para preencher com a ajuda do pesquisador. Este pediu opiniões sobre o conteúdo ("O que você 
acha do conteúdo do site?"), a aparência ("O que acha da aparência?") e navegação (“Quão fácil é navegar o site?”).

Embora os participantes tenham sido convidados a fornecer uma "execução comentário" em relação ao que sentem sobre cada local, na prática consistia em o pesquisador lembrá-los das questões sobre o formulário de avaliação, não houve comentários futuros ou para esclarecer alguns pontos. Os participantes permaneceram em seus próprios terminais de computador e foram convidados a trabalhar sozinhos ou em pares. Decidiu-se que todos os participantes trabalhariam com o mesmo local ao mesmo tempo. O que não teria sido o caso, se eles tivessem trabalhado em sites diferentes. Depois de terem completado as atividades descritas abaixo, eles se mudaram para o segundo e depois terceiro site.

Claramente, o problema surge da influência da ordem dos sites. No entanto, isso foi minimizado na primeira fase do estudo, fazendo com que o site que foi marcadamente diferente - o "mainstream" do site Newham fosse colocado por último. Poderia ser sugerido que, como o local era sem dúvida mais difícil, fosse o primeiro a ter sido examinado, enquanto mentes ainda estavam frescas. No entanto, considerou-se que isso teria feito os participantes desconfiados ou preocupados, olhando para os outros, e também poderia ter sido muito cansativo. Os participantes tiveram um intervalo de 30 minutos antes de enfrentar o site mais difícil.

Aos participantes foi dada a oportunidade de explorar os sites como eles quisessem e, em seguida, foram convidados a completar uma série de tarefas definidas, como descrito abaixo.

Definir tarefas:Três tarefas foram definidas para a primeira etapa e, em seguida, duas na segunda. Cada tarefa era tão equivalente quão possível, levando em consideração a diferença entre os sites. A empresa deles, obviamente, permitiu que o pesquisador avaliasse o site em termos de praticidade e ajudou a estruturar $o$ uso do site participante, a fim de oferecer-Ihes uma experiência mais abrangente de cada interface e assim instruir ainda mais a formação de suas opiniões sobre cada um deles. As tarefas eram mais variadas em tópico do que apenas à procura de trabalho, porque era o Website que estava sendo examinado e não simplesmente a seção de emprego. Além disso, os participantes, embora à procura de emprego, tinham outros interesses sobre os quais poderiam encontrar informações no site. $\mathrm{Na}$ verdade, para a segunda etapa do estudo, não foi considerado o tema do emprego, um dos sites, escolha de Dobson, não oferece qualquer informação sobre 
oportunidade de emprego. A seguir, um exemplo de uma tarefa que é sobre dinheiro:

Q1: Onde você acha que você vai encontrar informações sobre o dinheiro?

Click no link

Q2: Agora, onde está a seção sobre "Usando um caixa eletrônico"?

- Click no link

Q3: O que dizer sobre o seu número ou senha?

O site para o qual essas questões foram formuladas (Newham Leitura Fácil) tem links diretamente para as informações sobre o dinheiro e depois há um link explicitamente para 'Usando um caixa eletrônico'. Esta é, portanto, uma boa tarefa com a qual a sessão pode ser iniciada. Especificamente, ela requer que os participantes:

- Reconheçam um conteúdo ou menu e sejam capazes de digitalizá-lo;

- Reconheçam e ativem o link 'Money';Reconheçam e ativem o link 'Usando um caixa eletrônico';

- Rolem a página para encontrar informações sobre números PIN.

\section{A coleção de dados}

Preferências foram dadas em relação a conteúdo, a estrutura e a aparência dos sites. Os métodos utilizados foram a observação participante / entrevistas e sistema de classificação de um "sorrisômetro". Este último foi utilizado de duas formas, primeiro como um suporte para as pessoas que têm dificuldades em falar ou, pelo menos, iniciar uma conversa. Desta maneira, uma escolha de determinada classificação poderia ser usada como um foco para iniciar uma conversa (ou, pelo menos, uma opinião mais articulada). Seu outro uso era para medir o "encaixe" entre classificações e pontos de vista expressos. Isso foi considerado um teste útil para qualquer trabalho possível posterior com as pessoas para quem a auto expressão era mais difícil, com o fundamento de que, se a classificação e o discurso pareciam correlatos, que validou o primeiro. A escala original consistia de três ícones que retratam rostos com expressões que mostram, respectivamente, um sorriso, para 'gostar'; uma expressão neutra, 'sem opinião / neutra' (descrito para os participantes como 'quando você não gosta'); e uma cara fechada, para 'antipatia' (ver Tabela 1). Estes foram semelhantes aos sistemas de classificação utilizados por outras pessoas (por exemplo, Combes et al, 2004) e descrito por Atwood (1998) em relação 
aos do espectro autista. A escala usando apenas um ícone neutro, um negativo e um positivo foi projetada para minimizar possíveis problemas de incompreensão ou preconceito. Como uma medida de acompanhamento das entrevistas descritas a seguir, constituiu-se um ponto de vista concreto, sempre supondo os termos 'gostar' e 'antipatia' para serem interpretados pelos participantes da mesma forma que aquele que é geralmente aceito. No viés de linguagem, a aquiescência foi reduzida pelo pesquisador, deixando a seleção para o participante e apenas quando necessário avisar: 'qual a imagem que você vai escolher', (evitando perguntar 'este ou este... ') para que o problema de ordem não surgisse.

Aos participantes foi solicitado fornecer uma "execução comentário", em que eles foram incentivados a articular opiniões espontâneas sobre cada página acessada e, então, oferecer suas comparações entre sites. Tanto quanto possível, eles receberam carta branca para dizer o que sentiam em relação a cada local, mas o pesquisador também fez perguntas, com base em pontos de vista oferecidos e em resposta às ações empreendidas. No fim deste processo e antes da discussão de pós-sessão, aos participantes foi solicitado classificar o local utilizando a escala de classificação discutida anteriormente.

Para ambas as entrevistas e a escala de classificação, os participantes foram convidados a considerar:

- Site design e estética: Era solicitado, por exemplo, O que você acha da aparência? Do que você gosta, em relação a isso? A interrogativa polar (pergunta fechada, 'sim/não') Você gosta da aparência do site? foi evitada;

- Estrutura e navegação (e a facilidade com que a informação poderia ser encontrada): perguntas aqui eram "Foi fácil encontrar a informação?" "Foi fácil chegar em uma página a partir de outra?", mais uma vez, ao invés de 'Foi fácil...?'

Conteúdo da informação, em termos de acessibilidade e relevância: perguntas aqui foram: 'Mostre-me que partes do site você acha que usaria' e 'Que partes do site foram úteis?' Essa foi realmente uma área muito difícil de questionar, e assim os participantes foram inquiridos apenas uma vez, e só quando o pesquisador ou tutor que os acompanhava considerou que eles seriam capazes de 
entender e responder apropriadamente. Claro, era atraente perguntar "O site foi útil?", o que talvez poderia ter sido seguido (dada uma resposta afirmativa) com "De que maneira?" Esta opção foi rejeitada, pois violaria o princípio de não pedir interrogativas polares (na tentativa de evitar viés aquiescência) e também porque possivelmente colocaria os participantes em uma posição um pouco embaraçosa se eles não fossem capazes de responder a sessão seguinte.

Geralmente, como acontece com outros trabalhos do escritor atual - Williams e Hennig (2015) -, que encontrou indícios de que um menu vertical pode ser mais difícil de navegar do que o horizontal, de interesse particular não houve qualquer diferença de opinião em relação à aparência do menu. Como descrito acima, o primeiro é usado por Movingonup (que também usa uma aparência circular) e o último por ambos, Newham Leitura Fácil e sites de Newham Borough Council. Um arranjo de menu em grelha também foi utilizado, como favorito pela Escolha de Dobson e adotado para a home page de Pete Leitura Fácil. Os participantes foram, portanto, solicitados diretamente a comparar e comentar sobre aparências de menu a este respeito e a classificar o site em três categorias, depois de terem realizado as tarefas, em um formulário entregue a eles no início da sessão. Este é reproduzido (reduzido) no Quadro 1, que também mostra os ícones do original.

Quadro 1 - Formulário de avaliação original para capturar preferências do site ${ }^{2}$

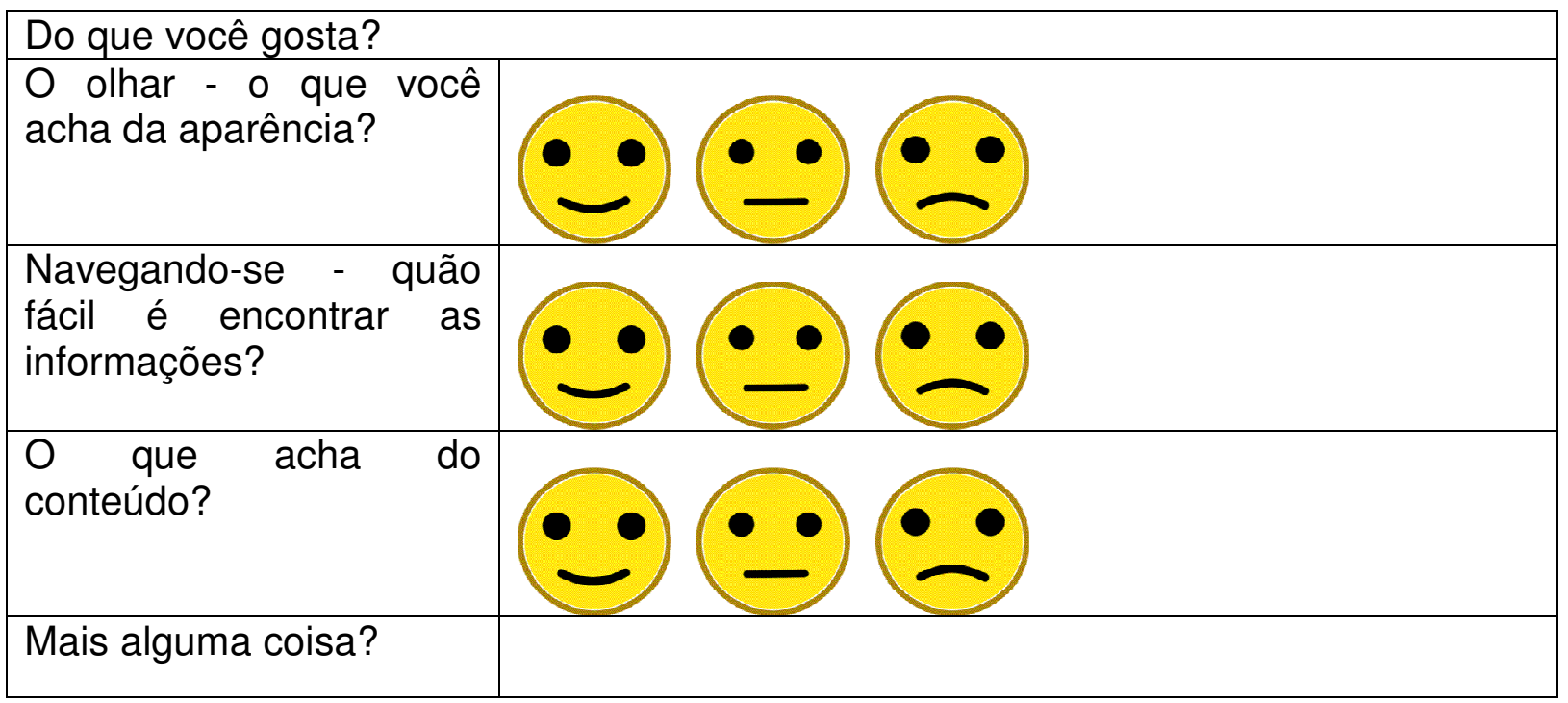

Fonte: Elaborado pelo Autor.

\footnotetext{
${ }^{2}$ Note-se que o topo de cada célula mão direita é onde os comentários são gravados.
} 
Este foi, então, utilizado pelo pesquisador em questões pós-tarefa. Os resultados de optar por este método são discutidos sob o título 'Questões Metodológicas', abaixo. Conforme descrito em mais detalhes a seguir, os resultados sugeriram que o ícone de 'neutro' não foi utilizado, pode não ter sido bem compreendido. Uma versão modificada foi, por conseguinte, utilizada, os detalhes estão descritos abaixo.

\section{A análise dos dados}

Embora este tenha sido essencialmente um estudo qualitativo, houve número suficiente de participantes para tentar a análise quantitativa bruta de correspondência comentários para o sistema de classificação sorridente. Assim, os comentários feitos, ou 'livre' ou em resposta ao entrevistador pesquisador, foram codificados por tópico e resultado do 'sorrisômetro'. Por exemplo, o comentário (sobre Newham Borough Council) "É apenas um monte de palavras" foi codificado sob o design do site e categoria estética, ao invés de ser em relação ao conteúdo, mas a aparência da página foi classificada com uma 'cara fechada' pelo participante. Alguns comentários por livre e espontânea vontade ou exigido pelo pesquisador eram separados em classificações tais como navegação ou aparência.

Alguns comentários oferecidos quando os participantes foram solicitados a descrever, por exemplo, o conteúdo, endereçado realmente a um ou outro atributo a ser analisado, em relação a navegação ou aparência, foram codificados sob o título que mais relacionava os atributos ao invés de ser a respeito do atributo sobre o qual as perguntas foram direcionadas (ou seja, em alguns casos, quando perguntado sobre o conteúdo, respostas relacionadas à navegação, etc).

\section{RESULTADOS}

\section{Preferências dos Melhores}

A Tabela 2 compara os sites em termos do 'sorrisômetro', classificações dadas a eles pelos entrevistados durante a primeira rodada do estudo. Os números nas células representam o número de participantes. 
Tabela 2: Teste de referência $P$ : avaliações resultados da escala, o primeiro round $(n=12)$.

\begin{tabular}{|c|c|c|c|c|}
\hline Site & Aspecto & Sorriso & Neutro & $\begin{array}{l}\text { Cara } \\
\text { fechada }\end{array}$ \\
\hline & & $\because$ & $\because$ & $\because$ \\
\hline \multirow{3}{*}{$\begin{array}{l}\text { Newham } \\
\text { Leitura Fácil }\end{array}$} & $\begin{array}{l}\text { Aparência } \\
\text { estética }\end{array}$ & 10 & 0 & 2 \\
\hline & $\begin{array}{l}\text { Estrutura } \mathrm{e} \\
\text { navegacão }\end{array}$ & 7 & 1 & 4 \\
\hline & $\begin{array}{l}\text { Conteúdo de } \\
\text { informacãa }\end{array}$ & 10 & 1 & 0 \\
\hline \multirow{3}{*}{ Movingonup } & $\begin{array}{ll}\begin{array}{l}\text { Aparência } \\
\text { estética }\end{array} & \text { e }\end{array}$ & 11 & 1 & 0 \\
\hline & $\begin{array}{l}\text { Estrutura } \\
\text { navegação }\end{array}$ & 11 & 0 & 2 \\
\hline & $\begin{array}{l}\text { Conteúdo de } \\
\text { informação }\end{array}$ & 10 & 0 & 2 \\
\hline \multirow{3}{*}{$\begin{array}{l}\text { Newham } \\
\text { Borough } \\
\text { Council }\end{array}$} & $\begin{array}{l}\text { Aparência e } \\
\text { estética }\end{array}$ & 0 & 1 & 11 \\
\hline & $\begin{array}{l}\begin{array}{l}\text { Estrutura } \\
\text { navegação }\end{array} \\
\text { e }\end{array}$ & 1 & 0 & 11 \\
\hline & $\begin{array}{l}\text { Conteúdo de } \\
\text { informação }\end{array}$ & 1 & 0 & 11 \\
\hline
\end{tabular}

Fonte: Elaborado pelo Autor.

Exceto pelo site do Newham Borough Council, havia muitas classificações positivas (rosto sorridente). Para o site Movingonup, por exemplo, 11 participantes escolheram o sorriso em duas das três categorias e 10 para a terceira, e em relação ao Newham Leitura Fácil, 10 escolheram a mesma categoria conteúdo da informação. Essas classificações estavam em contraste marcante com aquelas para o site do Newham Borough Council, que atraiu 11 'caras fechadas' de classificações ao longo dos três atributos que estavam sendo considerados. Assim, as classificações de destaque tiveram um contraste aparente em visões sobre o mainstream e os outros sites. Razões expressas para as classificações dos participantes são apresentadas abaixo.

Nota-se também a falta de uso da classificação "neutra". Isto levanta a questão de seu valor, tanto em termos de seu valor como uma categoria quanto à interpretação dada a ela. Seguindo em frente, portanto, do próprio instrumento, a opção "neutro" foi - como observada na seção metodologia - descrita para os participantes como "não gosto nem antipatizo" ao atributo que está sendo 
considerado. Pode-se argumentar, portanto, que este não é o mesmo que "sem opinião" e que é mais fácil para as pessoas com deficiência aprender a pensar mais em termos binários de gostar ou não gostar de alguma coisa. Em sua análise de "sem opinião" como resposta, Krosnick et al (2002) opinam que a exclusão de tal categoria não diminui a qualidade dos dados acumulados.

Outro aspecto do instrumento é a opção individual positiva ou negativa. Este foi, naturalmente, planejado de forma simples para facilitar o exercício simples. No entanto, a falta de uso da opção neutra levou ao uso pesado das avaliações positivas e negativas. Para a segunda rodada do estudo, para combater este problema, foi utilizada uma escala de avaliação de quatro pontos, com o "gosto muito", "gosto um pouco", "não gosto" e "odeio", como opções. Onde houvesse hesitação, o pesquisador simplesmente dizia: 'você não precisa escolher qualquer um deles, se você não tem uma opinião'. Para esta eventualidade, um "não opinião" teria sido gravado, embora a situação não tenha surgido. Tal como acontece em uma rodada do estudo, no entanto, esta rodada foi acompanhada pelo pesquisador, provocando comentários e utilizando a escala como um ponto de foco.

Os resultados da avaliação para esta rodada do estudo podem ser vistos na Tabela 3 , a seguir. 
Tabela 3: Teste de referência P: avaliações resultados da escala, segundo round ( $\mathrm{n}$ $=13$ )

\begin{tabular}{|c|c|c|c|c|c|}
\hline Site & Aspecto & $\begin{array}{l}\text { Como } \\
\text { muitos }\end{array}$ & $\begin{array}{l}\text { Como um } \\
\text { pouco }\end{array}$ & $\begin{array}{l}\text { Não } \\
\text { gostam } \\
\text { de um } \\
\text { pouco }\end{array}$ & $\begin{array}{l}\text { Não } \\
\text { gostam } \\
\text { muito }\end{array}$ \\
\hline & & $\because$ & $\bullet$ & $\ddot{\bullet}$ & $\ddot{\sim}$ \\
\hline \multirow{3}{*}{$\begin{array}{l}\text { Pete Fácil } \\
\text { leitura }\end{array}$} & $\begin{array}{l}\text { Site design } \\
\text { e estética }\end{array}$ & 10 & 3 & 0 & 0 \\
\hline & $\begin{array}{l}\text { Estrutura e } \\
\text { navegação }\end{array}$ & 9 & 3 & 1 & 0 \\
\hline & $\begin{array}{l}\text { Conteúdo } \\
\text { de } \\
\text { informação }\end{array}$ & 6 & 7 & 0 & 0 \\
\hline \multirow{3}{*}{$\begin{array}{l}\text { Escolha de } \\
\text { Dobson }\end{array}$} & $\begin{array}{l}\text { Site design } \\
\text { e estética }\end{array}$ & 10 & 3 & 0 & 0 \\
\hline & $\begin{array}{l}\text { Estrutura e } \\
\text { navegação }\end{array}$ & 7 & 3 & 3 & 0 \\
\hline & $\begin{array}{l}\text { Conteúdo } \\
\text { de } \\
\text { informação }\end{array}$ & 8 & 5 & 0 & 0 \\
\hline \multirow{3}{*}{ Movingonup } & $\begin{array}{l}\text { Site design } \\
\text { e estética }\end{array}$ & 9 & 3 & 1 & 0 \\
\hline & $\begin{array}{l}\text { Estrutura e } \\
\text { navegação }\end{array}$ & 8 & 5 & 1 & 0 \\
\hline & $\begin{array}{l}\text { Conteúdo } \\
\text { de } \\
\text { informação }\end{array}$ & 9 & 4 & 0 & 0 \\
\hline
\end{tabular}

Fonte: Elaborado pelo Autor.

Tal como é mostrado na tabela, a escala de classificação alterada produziu avaliações mais variadas. Tanto o 'gosto um pouco' e 'gosto muito' foram bem utilizadas, com pelo menos três dos 13 participantes, utilizando a primeira opção em todos os casos e, portanto, não mais do que 10 a última opção. Como cada um dos sites foi produzido especificamente para pessoas com deficiências mentais, talvez não seja nenhuma surpresa haver poucos 'não gosto de' e nenhum de classificação "odeio".

\section{Preferências expressas}

Ficou claro a partir de vários comentários e perguntas as respostas em que havia opiniões semelhantes sobre o portal Newham Leitura Fácil e o site 
Movingonup na primeira rodada e também com todos os sites mostrados na segunda rodada. Os participantes reconheceram que cada site era direcionado a pessoas em situações semelhantes às deles, e destacaram preferência para o uso de fotos. Áudio foi apreciado quando oferecido (Newham Leitura Fácil, Escolha de Dobson). Em resumo, os comentários forneceram dados muito mais ricos do que o sistema de classificação empregado. Eles estão resumidos a seguir, começando com o site do Newham Borough Council:

Site design e estética: O Borough, aparência da página Conselho Newham, foi criticado muito fortemente "É apenas uma carga de escrita - não é bom se as pessoas não sabem ler", "não há bastantes fotos", "parece chato". Tamanho do texto era um problema também, com relatos de o texto ser muito pequeno, embora a quantidade de texto parecesse ser a principal preocupação.

Estrutura e navegação:Três aspectos não foram bem recebidos pelos participantes. Em primeiro lugar, a estrutura hierárquica do menu estava simplesmente confusa: "Eu não entendi", "quando eu cliquei, tudo o que eu recebi foi uma lista", "eu me perdi". Em segundo lugar, considerou-se que havia muitas opções na lista. Claramente, a disposição hierárquica ajudou a reduzir o número de opções. O problema era que o site possuía tanta informação sobre tantos temas que era difícil ter uma estrutura de menu que fosse breve e simples. Finalmente, a natureza vertical das entradas conteúdo foi criticada - especialmente a lista das colunas da direita. Isto foi principalmente porque as entradas caíam abaixo do nível da tela (um problema relacionado aos números de opções) e também porque os participantes consideraram que era mais difícil ler verticalmente no lado direito da página. ("Você não pode ver todas as opções", "Eu não gosto de ler assim [na vertical, no lado direito da página]"). Em razão do modo habitual de ler a partir da esquerda, e também horizontalmente, talvez não tenha sido nenhuma surpresa que ter que adotar uma prática contrária seria visto como problemático. Esta questão também foi discutida em detalhes (WILLIAMS; HENNIG, 2013, 2015; WILLIAMS, 2013a; WILLIAMS, 2013b).

Conteúdo de informação: Isso também foi mal recebido pelos participantes que fizeram comentários sobre o conteúdo (oito, dos 12 participantes). As pessoas achavam que "a informação não está clara", e conter "palavras difíceis". Resumindo, Newham Borough Council Website não foi visto como sendo apto para pessoas como eles: "Esta informação não é útil para mim, eu não quero olhar para esse tipo 
de coisa", "Pode ser bom para as pessoas que trabalham para o Newham Borough Council ... nada útil para mim!"

O site Movingonup foi usado para ambas as rodadas do estudo e era muito admirado. Os participantes certamente pareciam ser mais interessados neste site em comparação aos outros, e passaram mais tempo nele.

Site design e estética: as fotos foram particularmente valorizadas: "Eu gosto das fotos", "as fotos são agradáveis", "é fácil ver quais são os temas. Da mesma forma, os personagens nas fotografias foram apreciados: "você pode ver quem está escrevendo", "torna-se real", ou mais simplesmente "é bom ver as fotos" (um exemplo que pode ser visto na Figura 7).

Figura 7 - página do site Movingonup (detalhe), mostrando um exemplo de fotografias utilizadas

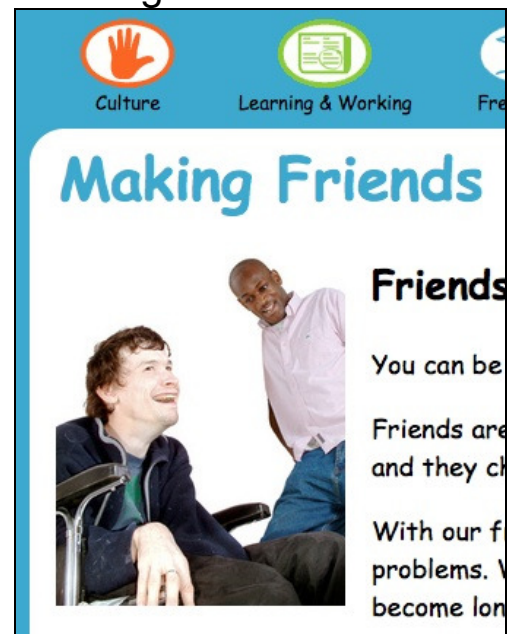

Fonte: www.movingonup.info (2012).

Os participantes também expressaram uma preferência para o tamanho de letras grandes, o que foi descrito como "fácil de ler" e "melhor do que [Newham Borough Council]".

Estrutura e navegação: A inativa estrutura circular do menu foi muito apreciada: "Essa roda é o máximo", "o círculo é legal". Na verdade, ambos os desenhos do menu deste site foram considerados melhores que os outros locais - 0 arranjo horizontal teve preferência em relação ao vertical: "este é um fácil olhar", "parece certo", "eu gosto desta forma" - comentários que sugerem que um estilo horizontal pode ser mais "natural", principalmente para as pessoas que ainda se encontram no processo de aprender a ler ou que são incapazes de fazê-lo sem esforço. 
As setas para a frente e para trás mencionadas na descrição do site foram utilizadas por apenas quatro dos 12 participantes na primeira fase do estudo e seis de 13 na segunda fase. Assim, apesar das opiniões expressas serem positivas, nem todas as áreas que facilitam a navegação foram utilizadas e, portanto, grande parte das informações sobre o local não foi acessada, afetando o desempenho da tarefa. Portanto, o fato de a página utilizar setas para facilitar a navegação para a próxima página ao invés de rolar para acessar as informações não significa necessariamente que o mesmo será acessado com mais facilidade. Neste caso, pelo menos, isso não aconteceu.

Conteúdo de informação: Os participantes mostraram apreciação disso também, embora - como foi o caso acima - grande parte do conteúdo foi escondido até o ponto em que foi mostrado aos participantes como acessá-lo. Os tópicos mais populares foram "Aprender e trabalhar" e "tempo livre" (e, dentro destes, "fazer amigos"). O subtema de fazer amigos também foi popular, embora aqui alguns dos comentários foram mais direcionados ao valor de ter amigos ao invés do valor das informações no site.

\section{O site Leitura Fácil Newham foi avaliado da seguinte forma:}

Site design e estética: participantes gostaram, em particular, do número (e conteúdo) das fotos digitais incluídas ("as fotos são ótimas", "[as fotos] mostram situações reais [ou seja, por exemplo, utilizando o caixa eletrônico, etc]". Não menos que 10 participantes fizeram comentários positivos sobre este aspecto do site, justificando sua classificação 'Sorrisômetro'. Um dos participantes afirmou que as fotos eram importantes porque ilustravam cada frase em cada página. As fotos também foram apreciadas por dois participantes, uma vez que essas fotos foram tiradas e incluíam pessoas com dificuldades de aprendizagem. Considerando o áudio nesta seção (ou seja, como parte do design do site), não foi bem utilizado. $\mathrm{Na}$ verdade, além de um participante ter acessado vários clipes de áudio, outros participantes só o fizeram quando eles foram perguntados se eles tinham usado, o que fizeram logo em seguida. Dois participantes julgaram os clipes difíceis de entender (que foram gravados pelas pessoas com dificuldades de aprendizagem em si), embora outros tenham dito que era "bom de ouvir a conversa", adicionando que seria melhor para as pessoas com dificuldades de leitura. 
Estrutura e navegação: Este foi visto muito positivamente. Tiveram três comentários negativos - um participante disse que as imagens eram muito pequenas nas entradas de cada página e dois outros disseram que havia muitas páginas.

Conteúdo de informação: Isso foi muito bem recebido. Mais uma vez, a atração foi a representação de pessoas com deficiência mental, embora, como indicado acima, o conteúdo mostrando as atividades diárias tenha sido particularmente apreciado. Claramente, e talvez não surpreendentemente, os participantes relacionados com ocorrências cotidianas concretas, tais como imagens de pessoas jogando boliche ou aprendendo a atravessar a rua, e não o conteúdo mais abstrato relacionado a dinheiro ou benefícios destacados no site Movingonup esta frase esta com sentido incompleto. Dito isto, o site Newham Leitura Fácil contém informações sobre o dinheiro, mas elas tendem a ser baseadas nas experiências de leitores potenciais - como o uso de um caixa eletrônico ou gastar dinheiro (embora, sem dúvida, a informação como "Nós gastamos nosso dinheiro em compras para camisas, vestidos, alimentos, calças, sapatos e atividades de lazer, como discotecas, drama, parede de escalada, natação, cinema e academia " seja de uso prático limitado). Mais uma vez, a seção de lazer foi a mais popular, com boliche sendo acessado por aqueles que olharam para esta seção - possivelmente por ser o primeiro item do menu.

\section{Comentários para Pete Leitura Fácil foram:}

Site design e estética: para a segunda rodada, o site de Pete Leitura Fácil (uma versão adaptada do Newham Leitura Fácil) foi usado com adaptações baseadas nos comentários dos participantes. Por exemplo, menos itens de menu foram criados, a posição do menu foi horizontal, havia texto maior e fotos (ao invés de ícones). Isso foi muito apreciado ("Eu gosto dele porque há fotos"), com comentários positivos sobre a estrutura de grade na página inicial ("O menu é muito claro") e sobre a aparência geral, o que foi dito por um participante "para olhar realmente bom." O texto maior foi comentado positivamente por dois participantes.

Estrutura e navegação: Novamente, os comentários foram em geral positivos ("Tudo o que você precisa é abrir uma página e, em seguida, uma outra", ou seja, para 
começar a partir da página inicial para uma página de submenu e depois para uma página de informações. Outro comentário: "Você só precisa clicar e a escrita aparece". Um participante, no entanto, não percebeu ou reconheceu o botão 'voltar' e teve que perguntar como voltar para a página anterior.

Conteúdo da informação: A informação foi restrita para um limite de mais ou menos 50 palavras por assunto, no entanto, um participante disse que "havia muita informação e era fácil de ler." Os próprios temas foram aprovados ("O que precisamos"). No entanto, embora ninguém tenha classificado informação em qualquer uma das categorias 'antipatia', havia mais "gosto um pouco" do que "gosto muito" como respostas. Apesar de um empurrão de leve e sugestões para comparar o conteúdo com o conteúdo dos outros dois sites, ambos receberam melhor pontuações, não foi possível determinar as razões para estas diferenças.

\section{Escolha de Dobson comentários foram:}

Site design e estética: A aparência e design do site também foi muito bem apreciado - em particular a estrutura do menu e aparência, descrita como "bem organizado", "colorido", bem como em termos mais gerais, tais como "bom" e " legal ". O único ponto negativo, apontado por dois participantes, era que havia "muito branco" ou "muito espaço" na tela, o último comentário foi de um participante que tinha inicialmente dito que a página precisava ser mais colorida (foi perguntado em seguida: "De que maneira?").

A mudança entre o menu e o submenu apresentava caixas que mudavam dinamicamente (Veja Figura 6). Surpreendentemente, ninguém mencionou isso (e o pesquisador queria evitar o "Você gosta deste aspecto?" Tipo de pergunta polar). Como mencionado acima, o site também continha áudio. Ao contrário de Newham Leitura Fácil, este foi ativado automaticamente passando o mouse sobre a opção (sem clicar). Dois participantes disseram que gostaram e outros disseram que eles gostaram da imagem real da cabeça falante.

Estrutura e navegação: Isso não foi tão bem recebido quanto à aparência, principalmente porque, quando uma entrada de menu era clicada, ao invés da página de abertura, uma voz era ativada dizendo "Este é o botão [tema]. Se você quiser saber mais sobre [tema] clique neste botão." Parece que ao clicar novamente 
no link durante este áudio não havia efeito - era preciso esperar até o final e, em seguida, ativá-lo. Isso se provou frustrante, embora apenas três pessoas avaliaram a estrutura e navegação como "não gosto um pouco" e ninguém "não gosto muito". Curiosamente, dois participantes mencionaram o site ter muitas ligações ou tópicos - tanto de uma forma positiva. Isto contrasta com os comentários feitos sobre Newham Leitura Fácil, o que foi criticado por ter muitas entradas do menu - um claro exemplo da eficácia de uma boa organização.

Conteúdo de informação: Como mencionado, este site funciona apenas como um portal - as páginas de informações são de sites externos (não direcionados a pessoas com deficiência de aprendizagem). Assim, as avaliações deste foram baseadas apenas em sites colecionados. Todos participantes foram expostos à página de portal de cinema, pois uma das tarefas era encontrá-lo. Aqueles listados incluiu os sites oficiais de "Harry Potter',' Toy Story' e 'Mama Mia ', portanto, as avaliações foram baseadas nestes sites externos. Aqueles que eram perguntados sobre seus pontos de vista tendiam a discutir os méritos relativos aos filmes e não aos sites.

\section{QUESTÕES METODOLÓGICAS}

As questões inerentes a este estudo foram o uso de sistema de classificação do 'Sorrisômetro' e o cronograma de entrevista e técnica. Considerando o sistema de classificação em primeiro lugar, dois aspectos podem ser considerados:

- A correlação entre as classificações e comentários;

- O próprio instrumento.

Não é surpreendente que haja uma correlação entre comentários e classificações, pois os mesmos foram feitos ao mesmo tempo e no mesmo formulário. Teria sido possível e interessante pedir classificações após o elemento livre da atividade e antes das tarefas, e, em seguida, testar a correlação entre as classificações e os comentários feitos após as tarefas. No entanto, sem a estrutura do conjunto de tarefas, as classificações poderiam ter sido baseadas de uma 
maneira muito superficial, sem a estrutura necessária, que foi providenciada pelas tarefas.

A outra alternativa seria ter feito a observação não participante de modo que as classificações fossem dadas após a sessão Web completa, mas antes de qualquer intervenção do pesquisador. O problema que poderia ter surgido seria que as entrevistas feitas após as tarefas exigiriam o uso das lembranças das tarefas.

Solicitar a esse grupo (pessoas com deficiências de aprendizagem) opinião sem qualquer ajuda do pesquisador teria sido muito difícil e não resultaria em dados suficientes para justificar o esforço por parte dos participantes. Dados de qualidade teriam sido desperdiçados pelo entrevistador se o mesmo não solicitasse uma explicação em relação ao comportamento nos sites.

Em relação ao próprio instrumento, a sua primeira manifestação foi claramente insuficiente. A tentativa de torná-lo fácil de usar fez com que o mesmo fosse impreciso para ser considerado útil, com exceção de um assunto a ser explorado numa discussão mais aprofundada. De fato, o uso de uma categoria neutra não teve utilidade alguma. A maior variação nas respostas oferecidas pela segunda escala de classificação foi muito mais bem explorada pelos participantes. Embora houvesse muito mais classificações positivas do que negativas, os participantes foram mais seletivos, o que sugere que se tratava de uma medida mais sensível, que, desta forma, adicionados aos dados. Depreende-se que tem a vantagem adicional, considerando-se a variação das respostas, de ser mais fácil de usar.

No que diz respeito à forma de avaliação (um pequeno empurrão do pesquisador), as três áreas principais de interesse: conteúdo, design e estética, e navegação/estrutura, cobriam todos os aspectos dos sites. O questionamento funcionou bem e a evasão rigorosa de perguntas polares parecia evitar qualquer tendência para a aquiescência. COMENTÁRIO: provado que este grupo de pessoas, pelo menos, foi capaz de avaliar vários aspectos de sites e oferecer vistas construtivas sobre eles. A abordagem metodológica de avaliação permitiu que as contribuições fossem feitas durante a realização do exercício, quando vários recursos poderiam ser mostrados e onde o participante ou pesquisador pudessem mudar abas do navegador para permitir comparações fáceis. 


\section{CONCLUSÃO}

Este estudo analisou como as preferências dos usuários de sites com Dificuldades de Aprendizagem podem ser capturadas. Havia dúvidas em relação a eficácia do sistema de classificação original usado, a partir do qual apenas uma quantidade mínima de informação pôde ser obtida.

Contudo, a versão modificada produziu mais dados, combinados com 0 questionamento cuidadoso (por exemplo, evitar fazer perguntas cujas respostas fossem baseadas em o que eles acham que o pesquisador queria ouvir), foi possível extrair informações de número considerável de pessoas que têm dificuldade em articular as suas opiniões.

\section{REFERÊNCIAS}

ANTAKI C.; YOUNG N.; FINLAY, M. Shaping clients' answers: departures from neutrality in care- staff interviews with people with a learning disability. Disability and Society. v. 17, n. 4, p. 435-455, 2002.

ATTWOOD, T. Asperger's Syndrome: A Guide for Parents and Professionals London, Jessica Kingsley Press: 1998.

BARKBY A.; TALBOT, H.; LEE, A.; SKIRROW, P.; GREENHILL, E.; COOKSON, A.; WHITEHEAD, R.; HILEY, W. Parents with learning disabilities: perceived incidence and needs. Community practitioner, v. 82, n. 11, p. 34-7, 2009.

BEIRNE-SMITH, M.; ITTENBACK, R. F.; PATTON, J. R. Mental Retardation Upper Saddle River. 7. ed. New Jersey: Merrill-Prentice Hall, 2005.

BOOTH, T.; BOOTH, W. Sounds of silence: narrative research with inarticulate subjects. Disability and Society, v. 1, n. 1, p. 55-69, 1996.

BOYDEN, P.; MUNIZ, M.; LAXTON-KANE, M. Listening to the views of children with learning disabilities: an evaluation of a learning disability. Journal of intellectual disabilities, v. 17, n. 1, p. 51-63, 2013.

BREWSTER, S. J. Putting words into their mouths? Interviewing people with learning disabilities and little/no speech. British Journal of Learning Disabilities, v. 32, n. 4, p. 166-69, 2004. 
CHOI, J.; BAKKEN, S. Web-based education for low-literate parents in neonatal intensive care unit: Development of a Website and heuristic evaluation and usability testing. International Journal of Medical Informatics, v. 79, n. 8, p 565-575, 2010.

COMBES H.; HARDY, G.; BUCHAN, L. Using Q-Methodology to involve people with intellectual disability in evaluating person-centred planning. Journal of Applied Research in Intellectual Disabilities, v. 17, n. 3, p. 149-159, 2004.

DH (Department of Health). Valuing People: A New Strategy For Learning Disability for the 21st Century- A White Paper. London: Department of Health, 2001.

FANOU, S. (2008) Web 2.0: Engaging those with learning disabilities. In: WILLIAMS, R.; REMENYI, D. 7TH European Conference on e-Learning, 2008.

FINLAY, W. M. L.; WALTON, C.; ANTAKI, C. Promoting choice and control in residential services for people with learning disabilities. Disability and Society, v. 23, n. 4, p. 349-60, 2008.

HEAL, L. W.; SIGELMAN, K. C. Response biases in interviews of individuals with limited mental ability Journal of Intellectual. Disability Research, v. 39, n. 4, p. 331340, 1995.

KARREMAN, J.; VAN DER GEEST, V.; BUURSINK, E. Accessible Website content guidelines for users with intellectual disabilities. Journal of Applied Research in Intellectual Disabilities, v. 20, n. 6, p. 510-518, 2007.

KROSNICK, J. A.; HOLBROOK, A. L.; BERENT, M. K.; CARSON, R. T.; HANEMANN, W. M.; KOPP, R. J.; MITCHELL, R. C.; PRESSER, S.; RUUD, P. A.; SMITH, V. K.; MOODY, W. R.; GREEN, M. C.; CONAWAY, M. The impact of "no opinion" response options on data quality: Non-attitude reduction or an invitation to satisfice? Public Opinion Quarterly, v. 66, n. 3, p 371-403, 2002.

LEWIS, A.; NEWTON, H.; VIALS, S. Realising child voice: the development of cue cards. Support for Learning, v. 23, n. 1, p. 26-31, 2008.

MATAUSCH. K.; PEBOECK, B. EasyWeb - A study of how people with specific learning difficulties can be supported on using the internet In: MIESENBERGER, K.; KLAUS, J.; ZAGLER, W. Computers Helping People with Special Needs 12th International Conference. ICCHP: Vienna, Austria, 2010.

MEISENBERG. G.; WILLIAMS, A. Are acquiescent and extreme response styles related to low intelligence and education? Personality and Individual Differences, v. 44, n. 7 , p. 1539-1550, 2008.

MINNION. A.; STAPLES. P.; SINGH. R.; WILLIAMS, P. Beyond the Road Ahead London: University of East London Report submitted to the Social Care Institute of Excellence, 200.

MINNION, A.; WILLIAMS, P.; KENNEDY, H.; BUNNING, K.; Project @pple: elearning and the World Wide Web Report submitted to the ESRC PACCIT Programme. 2006. 
MURPHY, J. Talking Mats: a Low-Tech Communication Resource to Help People Express Their Views and Feelings Stirling: University of Stirling, 1997.

MURPHY, J.; CAMERON, L. Let your mats do the talking Speech and Language Therapy in Practice Spring, 2002.

RAPLEY, M.; ANTAKI, C. A conversation analysis of the acquiescence of people with learning disabilities. Journal of Community and Applied Social Psychology, v. 6, n. 3, p. 207-227, 1996.

ROTONDI, A. J.; SINKULE, J.; HAAS, G. L.; SPRING, M. B.; LITSCHGE, C. M.; NEWHILL, C. E.; GANGULI, R.; ANDERSON, C. A. Designing Websites for persons with cognitive deficits: Design and usability of a psychoeducational intervention for persons with severe mental illness. Psychological Services, v 4, n.3, p. 202-224, 2007.

SEVILLA, J.; HERRERA, G.; MARTINEZ, B.; ALCANTUD, F. Web accessibility for individuals with cognitive deficits: A comparative study between an existing commercial Web and its cognitively accessible equivalent. ACM Transactions on Computer-Human Interaction, v. 14, n. 3, p. 1-23, 2007.

SIGELMAN, C. K.; BUDD, E. C.; SPANHEL, C. L.; SCHOENROCK, C. J.; When in doubt, say yes: Acquiescence in interviews with mentally retarded persons. Mental Retardation, v. 19, n. 2, p. 53-58, 1981.

W3C (World Wide Web Consortium). Web Content Accessibility Guidelines (WCAG) 2.0. Disponível em: <http://www.w3.org/TR/WCAG/\#contents>. Acesso em: 03 de set. 2012.

WILLIAMS, P. Web site usability testing involving people with learning disabilities using only images and audio to access information. Journal of Research in Special Educational Needs, v. 13, n. 2, p. 142-151, 2013.

WILLIAMS, P.; HANSON-BALDAUF, D. Testing a Web information portal for people with learning disabilities. Journal of Research in Special Educational Needs, v. 10 , n. 1, p. 42-51, 2010.

WILLIAMS, P.; HENNIG, C. Optimising Website designs for people with learning disabilities. Journal of Research in Special Educational Needs, v. 13. Disponível em: <http://onlinelibrary.wiley.com/doi/10.1111/1471-3802.12034/abstract>.

WILLIAMS P.; HENNIG, C. The effect of web page menu orientation on retrieving information by people with Learning Disabilities. Journal of the American Journal of the Association for Information Science and Technology, v. 15, n. 1, p. 25-36, 2015.

WILLIAMS, P. Comparing the efficacy of different Web page interface attributes in facilitating information retrieval for people with mild Learning Disabilities. London: University College London (Unpublished PhD thesis), 2013. 
Title

Websites rating for with learning disabilities people

\begin{abstract}
Introduction: A growing body of literature is recognising the value of the World Wide Web as a tool that can be used to help people with learning disabilities access relevant and appropriately written and presented information.

Objective: This paper examines the website preferences of people with learning disabilities, the methods used and the methodological difficulties in eliciting preferences from this cohort.

Methodology: The methodological issues inherent were the use of the rating system and the interview technique.

Results:Participants recognised which two of the three sites were for and about themselves as a constituency, and they emphasised their liking for the use of pictures, especially as they were taken by and also featured young people with Learning Disabilities themselves. Regarding menu positioning, the horizontal arrangement was greatly preferred to the vertical one, and the unusual circular menu structure of one of the sites was greatly appreciated.

Conclusion: Examined how the preferences of website users with Learning Disabilities could be captured. There were question marks over the efficacy of the original rating system employed, from which only a minimum amount of information could be elicited. Combined with questioning it was possible to elicit considerable information from people who find it difficult to articulate their views.
\end{abstract}

Keywords: Usability. Learning difficulties. Websites rating. Learning disabled.

\title{
Título
}

Evaluación de sitios Web para personas con dificultad de aprendizaje

\section{Resumen}

Introducción: Un creciente grupo de literatura busca reconociendo el valor de la World Wide Web como una herramienta que puede ser usada para ayudar a las personas con dificultades el acceso aprendizaje relevante y apropiada por escrito y presentado información.

Objetivo: Este artículo examina las preferencias de sitios web de las personas con dificultades de aprendizaje, los métodos utilizados y las dificultades metodológicas en la obtención de las preferencias de este grupo.

Metodología: Las cuestiones metodológicas inherentes fueron el uso del sistema de calificación y la técnica de la entrevista.

Resultados: Los participantes reconocieron que dos de los tres sitios fueron para y acerca de sí mismos como un grupo, y ellos enfatizaron su preferencia por el uso de las imágenes, especialmente a medida que fueron tomadas por y también contó con los jóvenes con dificultades de aprendizaje en sí. En cuanto la colocación de menú, la disposición horizontal 
se prefiere en gran medida a la vertical, y la estructura del menú circular insólito de uno de los sitios fue muy apreciado.

Conclusiónes: Examinaron cómo podrían ser capturadas las preferencias de los usuarios de em sitio con dificultades de aprendizaje. Había dudas sobre la eficacia del sistema de clasificación original empleada, a partir del cual sólo una cantidad mínima de información podría ser provocado. Combinado con cuestionario fue posible obtener informaciónes considerables de personas que tienen dificultades para articular sus puntos de vista.

Palabras clave: Usabilidad. Dificultades de aprendizaje. Evaluación de sitios Web. Discapacidades para el aprendizaje.

Recebido em: 25.04.2014

Aceito em: 04.02.2015 